\title{
Mapas conceituais como recurso didático na formação continuada de professores dos primeiros anos do ensino fundamental: um estudo sobre conceitos básicos de astronomia
}

Luiz Marcelo Darroz

Cleci Teresinha Werner da Rosa

Álvaro Becker da Rosa

Carlos Ariel Samudio Pérez

\section{Resumo}

Neste artigo, relata-se uma experiência oriundade um curso de formação continuada de professores dos primeiros anos do ensino fundamental, amparado na teoria da aprendizagem significativa de David Ausubel, que utilizou mapas conceituais como recursos didáticos para a promoção da aprendizagem significativa. A proposta didática, cujo foco centrou-se no ensino de conceitos básicos de astronomia, foi desenvolvida com um grupo de vinte professores da rede pública municipal de Muliterno - RS. Os resultados obtidos demonstram que a oferta de um curso de formação continuada com ênfase nos conhecimentos prévios dos participantes e usando mapas conceituais como recurso didático pode ser considerada uma experiência promissora no sentido de complementar os currículos dos cursos de formação de professores.

Palavras-chave: Ensino de ciências na educação. Ensino de física. Mapas conceituais.

\begin{abstract}
In this article, we report an experience originated from a continuing education course for teachers of the first years of basic education, supported by the meaningful learning theory of David Ausubel, who used concept maps as educational resources to promote meaningful learning. The didactical proposal, which focus centered in the teaching of basic concepts of astronomy, was developed with a group of twenty teachers from the municipal public system of Muliterno, RS. The results obtained show that offering a continuing formation course with emphasis on the previous knowledge of the participants and using concept maps as educational resource may be considered a promising experience in order to supplement the curriculum of formation courses for teachers.
\end{abstract} education.

Key words: Concept maps. Physics teaching. Science teaching in basic 


\section{Introdução}

A astronomia vem despertando a curiosidade humana desde a mais remota antiguidade. O fascínio pelo céu tem levado o homem a observá-lo, a estabelecer teorias e a adquirir conhecimentos sobre o universo. Nessa tônica, o ensino de ciências, incluindo o eixo Terra e universo, é recomendado pelos Parâmetros Curriculares Nacionais (PCNs) desde a etapa inicial da escolarização (BRASIL, 1998). É, também, nos PCNs, sugerido que o professor desenvolva atividades práticas com seus alunos, tais como construir instrumentos simples, a exemplo do relógio de Sol e gnômons, ou realizar observações do Sol, da Lua, das estrelas e dos meteoros (BRASIL, 1998), o que evidencia a importância do assunto na sociedade, bem como sua influência sobre a cultura, o desenvolvimento tecnológico, a economia e o cotidiano do ser humano.

Tendo em vista que é nos primeiros anos do ensino fundamental que os estudantes entram em contato, pela primeira vez, com o conhecimento científico organizado, torna-se oportuno que, nesse nível de escolarização, eles compreendam os conceitos propostos e que a aprendizagem tenha vínculo com o contexto em que vivem. Nesse sentido, é essencial que os primeiros anos de ensino forneçam respostas às inquietações dos estudantes, estimulando-os para estudos posteriores, no entanto, isso somente será alcançado se o professor dominar o conteúdo que ensina e esse domínio dependerá, por sua vez, da presença desse conteúdo na sua própria formação (LANGHI; NARDI, 2005).

Os educadores dos primeiros anos do ensino fundamental, denominados "professores polivalentes", possuem formação em nível médio ou curso de licenciatura em Pedagogia. Esses cursos carecem de conteúdos próprios voltados para o ensino de ciências e, em particular, da astronomia (DARROZ, 2010), o que implica o fato de que vários docentes da educação básica somente voltam a ter contato com os conteúdos relacionados ao tema quando necessitam trabalhá-los em sala de aula (COSTA et al., 2010) .

Desde a década de 1980, trabalhos como os de Queiroz e Azevedo (1987), Franco Junior (1993), Bisch (1998), Silva (1999), Bretones (1999), Maluf (2000), Leite (2002), Langhi (2004), Langhi e Nardi (2007), Leite e Housume (2007), Gonzatti (2008) e Marques e Araujo (2010) evidenciam as dificuldades enfrentadas por esses professores em trabalhar conceitos relacionados com a ciência, justificadas pelas lacunas conceituais estabelecidas durante seu período de formação. Tais dificuldades - de ordem pessoal, metodológica, de formação, de infraestrutura, além de outras relacionadas às fontes de informações para docentes (LANGHI; NARDI, 2007) - refletem diretamente na atuação docente e trazem graves consequências para o ensino.

Frente a essa realidade, o presente trabalho tem como objetivo apresentar uma proposta didática que aborda os conceitos básicos de astronomia, fundamentada na teoria da aprendizagem significativa de David Ausubel, que se valeu do uso de mapas conceituais como 
recurso na busca por sanar as lacunas conceituais existentes na formação de professores dos primeiros anos do ensino fundamental.

\section{Referencial teórico: a aprendizagem significativa e os mapas conceituais}

A teoria da aprendizagem significativa de Ausubel prioriza a aprendizagem cognitiva. Nesta, a aprendizagem significativa é considerada como um processo pelo qual o novo conhecimento é articulado a uma determinada estrutura cognitiva prévia, denominada "subsunçor".

A estrutura cognitiva é entendida como o conjunto de conteúdos informacionais e a maneira como esses se organizam na mente de um indivíduo. Os subsunçores correspondem a conceitos ou ideias já existentes na estrutura cognitiva, capazes de ser "pontos de ancoragem", em que as novas informações encontrarão um modo de se integrar àquilo que a pessoa já conhece.

A aprendizagem significativa contrasta, fundamentalmente, com a aprendizagem mecânica, na medida em que, na primeira, a nova informação interage com algum subsunçor existente na estrutura cognitiva, já na segunda, a nova informação é armazenada de maneira arbitrária e literal, não interagindo com informações existentes na estrutura cognitiva. Assim, pouco ou nada contribui para a sua elaboração e diferenciação. Conforme Ausubel, porém, essas duas formas de aprendizagem se complementam, pois a segunda pode levar à primeira. Muitas vezes, um indivíduo pode aprender mecanicamente e somente mais tarde percebe que esse aprendizado se relaciona com algum conhecimento anterior já dominado. Com o passar do tempo, tais conhecimentos ficam mais complexos e são capazes de servir de "âncora" para novos conhecimentos.

A efetiva aprendizagem significativa está relacionada ao cumprimento de algumas condições. A primeira é que, para ser considerado potencialmente significativo, o material a ser aprendido deve ter estruturação lógica e deve poder relacionar-se com a estrutura cognitiva do estudante, de maneira não arbitrária e não literal. Também é necessário que o aprendiz apresente uma disposição para aprender significativamente, de modo que ele não possa ter a intenção de memorizar ou decorar o material, sendo essa a segunda condição para a ocorrência da aprendizagem significativa. Quando uma das duas condições não for satisfeita, ocorrerá, segundo Ausubel, uma aprendizagem mecânica. Para facilitar a aprendizagem significativa, o teórico recomenda o uso de organizadores prévios, que são materiais a serem propostos antes da utilização do material de aprendizagem propriamente dito, servindo de ponte entre o conhecimento prévio e os assuntos que se pretende ensinar. 
No decorrer da aprendizagem significativa, os conceitos que interagem com o novo conhecimento e servem de base para a atribuição de novos significados vão também se modificando em razão dessa interação, isto é, vão adquirindo novos significados e se diferenciando progressivamente. Esse processo dinâmico da estrutura cognitiva denomina-se "diferenciação progressiva” (MOREIRA, 1999).

Outro processo que ocorre durante o processo de aprendizagem significativa é o estabelecimento de relações entre conceitos subsunçores já constituídos na estrutura cognitiva. Os elementos existentes na estrutura cognitiva com determinado grau de clareza, estabilidade e diferenciação são combinados entre si para a aquisição de novos significados, originando uma reorganização dessa estrutura. Tal recombinação é chamada de "reconciliação integrativa".

Para promover integração, reconciliação e diferenciação de significados dos conceitos, Moreira (2006) apresenta os mapas conceituais como uma estratégia potencialmente facilitadora de uma aprendizagem significativa. Nas palavras do autor,

mapas conceituais foram desenvolvidos para promover a aprendizagem significativa. A análise do currículo e o ensino sob uma abordagem ausebeliana, em termos de significados, implicam: 1) identificar a estrutura de significados aceita no contexto da matéria de ensino; 2) identificar os conceitos subsunçores (significados) necessários para a aprendizagem significativa na matéria de ensino; 3) identificar os significados preexistentes na estrutura cognitiva do aprendiz; 4) organizar sequencialmente o conteúdo e selecionar materiais curriculares, usando as ideias de diferenciação progressiva $e$ reconciliação integrativa como princípios programáticos; 5) ensinar usando organizadores prévios, para fazer pontes entre os significados que o aluno já tem e os que ele precisaria ter para aprender significativamente a matéria de ensino, bem como para o estabelecimento de relações explícitas entre o novo conhecimento e aquele já existente e adequado para dar significados aos novos materiais de aprendizagem (MOREIRA, 2006, p. 8).

Esses mapas são diagramas que indicam relações entre conceitos, ou entre palavras usadas para representar conceitos. Podem ser considerados como um estruturador do conhecimento, na medida em que permitem mostrar como o conhecimento sobre determinado assunto está organizado na estrutura cognitiva de seu autor, que assim pode visualizar e analisar sua profundidade e extensão. Também, podem ser entendidos como uma representação visual utilizada para partilhar significados, pois explicam como o autor entende as relações e as hierarquizações entre os conceitos listados.

Nesse sentido, o mapeamento conceitual pode conduzir a profundas modificações na maneira de ensinar, de avaliar e de aprender e, em razão disso, pode ser usado em diversas 
situações do processo de ensino-aprendizagem, como um instrumento de análise do currículo, da técnica didática, do recurso de aprendizagem, ou simplesmente como um meio de avaliação (MOREIRA; BUCHWEITZ, 1993).

Na proposta aqui apresentada, tem-se o objetivo de que os docentes dos primeiros anos do ensino fundamental coloquem em reflexão seu modo de pensar e seus conhecimentos, por meio da negociação e do compartilhamento de novos significados dos conhecimentos. Assim, os mapas conceituais são utilizados como recursos didáticos para que cada participante torne-se ciente do que já sabe e observe a importância de compreender significativamente os conceitos relacionados à astronomia para o exercício de sua atividade profissional.

\section{O curso de formação continuada: os participantes e a metodologia aplicada}

O curso de formação continuada, que se desenvolveu no âmbito de um projeto de extensão, ocorreu em quatro encontros, realizados entre os meses de março e abril de 2012, sempre aos sábados de manhã, tendo como local de trabalho o laboratório de informática da Escola Estadual Raimundo Pelissaro, do município de Muliterno, no Rio Grande do Sul. O curso envolveu quatro professores do curso de Física - Licenciatura da Universidade de Passo Fundo e vinte professores dos primeiros anos do ensino fundamental do sistema público municipal de Muliterno.

Com o objetivo de coletar e reunir dados sobre a prática pedagógica de cada um dos participantes e de identificar os subsunçores presentes em suas estruturas cognitivas, inicialmente, solicitou-se que cada um deles respondesse a um questionário. Nesse instrumento, que se encontra no anexo 1 deste trabalho, as sete primeiras questões foram abertas e tinham o objetivo de caracterizar o grupo participante. Já as dezoito questões seguintes eram de múltipla escolha e foram elaboradas de tal forma que suas respostas permitissem a compreensão de quais eram os conhecimentos prévios dos respondentes acerca dos conceitos básicos de astronomia.

Os resultados demonstraram que, do grupo de professores participantes da proposta, 50\%trabalham há mais de dez anos nessa etapa de ensino; 90 \% possuem como formação de nível médio o curso na modalidade normal; $80 \%$ possuem graduação e, desses, $75 \%$ são licenciados em Pedagogia e os demais em Educação Física, Ciências Biológicas, Letras ou Geografia. Ainda, $60 \%$ desses docentes possui título de especialista nas áreas de psicopedagogia, educação especial e ensino interdisciplinar.

Durante a análise desse instrumento, evidenciou-se que, embora existam vários conceitos subsunçores presentes na estrutura cognitiva dos professores, esses profissionais não se sentem seguros para ministrar aulas de ciências que envolvam conceitos básicos de astronomia. Acreditase que esses conceitos foram incorporados às suas estruturas cognitivas ao longo de sua vivência cotidiana e profissional graças às informações que chegam ao seu alcance por intermédio dos 
livros didáticos, pelos meios de comunicação e pela observação do mundo natural, ou seja, de fenômenos astronômicos, como a ocorrência periódica dos dias e das noites, das estações do ano, das fases da Lua. No entanto, conforme demonstram os baixos índices de acerto das questões apresentadas na Figura 1, esses conhecimentos, na maioria das vezes, consolidam-se de forma incompleta ou equivocada.

As respostas ao questionário evidenciam, ainda, que, em virtude de o assunto não ter sido abordado, ou de ter sido abordado com pouca ênfase durante sua formação, esses professores precisam recorrer a diversos meios de informação para a elaboração de suas aulas, tais como sites da internet, filmes e documentários, mas principalmente livros didáticos. Segundo Langhi e Nardi (2007), embora, recentemente, o Ministério da Educação tenha realizado uma série de avaliações nos livros didáticos, assegurando a correção de muitos erros conceituais, vários outros equívocos continuam presentes nessas publicações, reforçando as concepções alternativas para a explicação dos fenômenos relacionados com a astronomia.

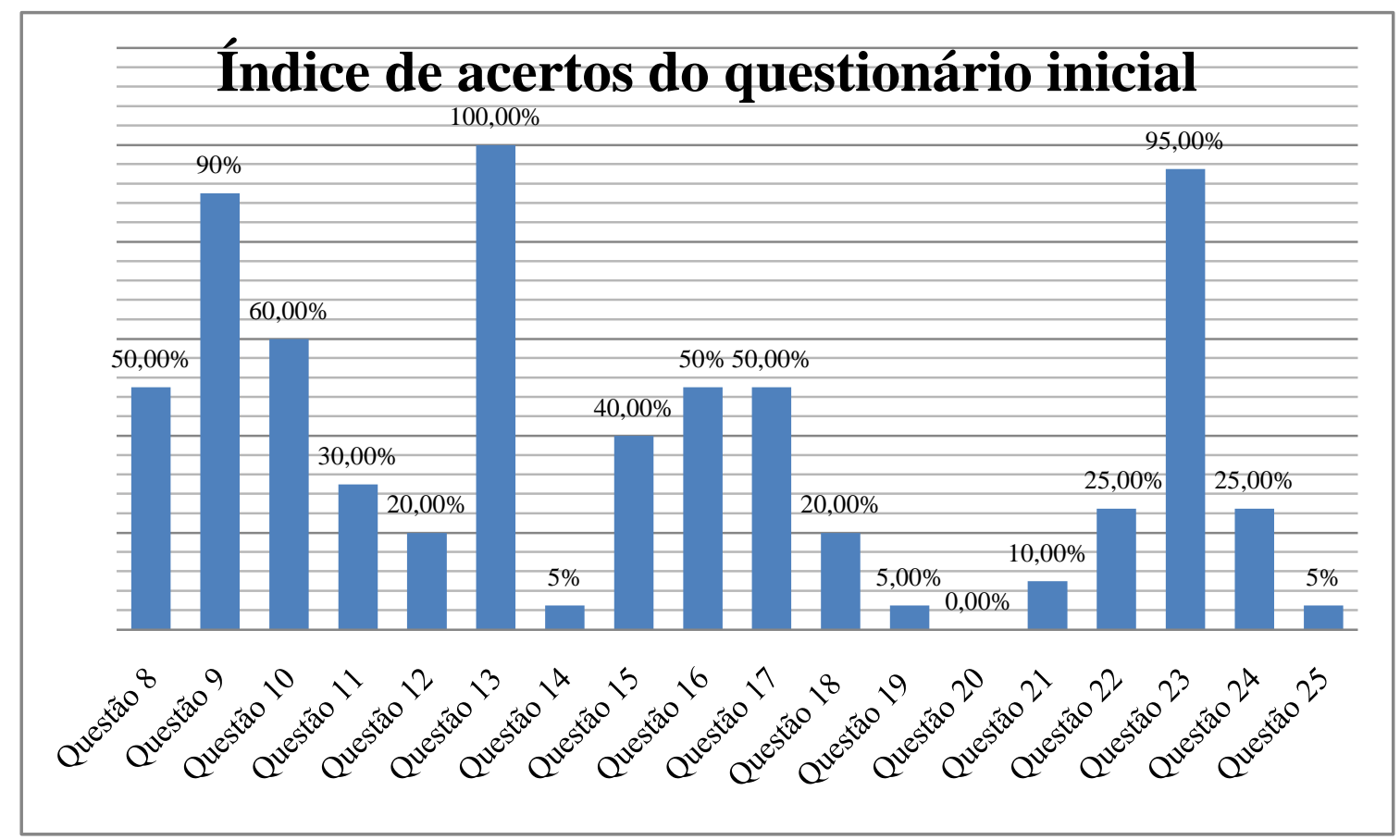

Figura 1: Índice de acertos das respostas dadas pelos professores ao questionário inicial.

A identificação dos conceitos subsunçores foi o ponto de partida para a estruturação da experiência didática apresentada neste relato. A partir dos resultados encontrados no questionário inicial, decidiu-se que, no curso, além das explicações dadas em sala de aula pelo professor, haveria um texto de apoio no qual estaria disponibilizado todo o conteúdo dos encontros. Optou-se por utilizar o texto contido no produto educacional Uma proposta para trabalhar conceitos de astronomia com alunos concluintes do curso de formação de professores na modalidade normal, de Darroz, Santos e Saraiva (2010). Tal escolha é justificada em razão de que 
esse material apresenta discussões sobre a origem do universo, as galáxias, sobre a formação e a evolução estelar, as constelações, o Sol, o Sistema Solar, o planeta Terra e seus movimentos, a Lua e suas fases e os eclipses, bem como em razão de que seu conteúdo privilegia, de forma simples, clara e com uma linguagem acessível aos professores, os aspectos qualitativos e a ênfase conceitual dos assuntos. Isso foi planejado para que as novas informações fossem facilmente relacionadas aos subsunçores presentes em suas estruturas cognitivas e para que proporcionassem, de maneira mais tranquila, a assimilação, a diferenciação progressiva e a reconciliação integrativa preconizada pela teoria ausubeliana.

Além disso, decidiu-se pela utilização de alguns instrumentos que serviriam de ponte entre o que o aprendiz já sabia e o que ele deveria saber (MOREIRA, 1999). Tais instrumentos eram selecionados de acordo com os assuntos abordados e apresentados na seção susequente.

Resumidamente, a estrutura dos encontros fundamentou-se nas ideias básicas da teoria da aprendizagem significativa de Ausubel: partindo dos conhecimentos prévios, utilizava-se um organizador para estabelecer a ponte entre o saber prévio e a nova informação, trabalhando-se, com base em um texto de apoio, um conteúdo potencialmente significativo para os professores. Nesse contexto, os mapas conceituais desempenharam a importante função não só de promover a diferenciação progressiva, como também de explorar, explicitamente, as relações entre proposições e conceitos -evidenciando semelhanças e diferenças significativas - e de reconciliar inconsistências reais ou aparentes. Ou seja, as atividades buscavam promover reconciliação integrativa.

Para isso, após a utilização dos organizadores prévios e de uma breve explicação oral do professor, o grupo era dividido em equipes menores, de cinco componentes, que, tendo como base o texto de apoio, elaboravam a primeira versão do seu mapa conceitual. Esse momento servia para que os professores participantes da proposta negociassem significados entre si, tornando claros os conceitos abordados, organizando-os em uma ordem sistemática, reforçando sua compreensão, elencando os conceitos-chave e resumindo suas inter-relações.

A primeira versão elaborada pelo grupo era, então, explicada oralmente para os demais. Tal encaminhamento tinha o escopo de que os participantes pudessem externalizar, de forma clara e explícita, a maneira como o conhecimento estudado estava formulado em sua estrutura cognitiva, compartilhando e atingindo novos significados acerca dos conceitos estudados, de maneira a fortalecer a aprendizagem significativa.

Após a apresentação, a explicação, a troca e as atribuições de significados idiossincráticos, os componentes retornavam aos seus grupos iniciais para reelaborar o mapa. Tal fato, contudo, não significava que a versão inicial dos mapas estivesse errada ou incompleta, pois, segundo Moreira (1999), os mapas conceituais são dinâmicos, estando constantemente em mudança no curso da aprendizagem significativa. Durante a exposição da versão preliminar do mapa, a 
estrutura cognitiva de cada participante estava constantemente se reorganizando por diferenciação progressiva e reconciliação integrativa e, por consequência, mapas traçados num determinado instante são diferentes em outro.

\section{Desenvolvimento da proposta: os encontros e alguns mapas produzidos}

Durante os encontros, foi utilizado o softwareCmap Tools (CAÑAS et al., 2003) para a construção dos mapas conceituais. Esse programa, que permite gravar todos os passos da construção dos mapas e reproduzir, a qualquer momento, dinamicamente, todas as modificações realizadas, possibilita, a partir da comunicação/colaboração, a participação ativa de todos os envolvidos nesse processo. Dessa forma, viabiliza acompanhar a construção, a elaboração e a representação dos conceitos envolvidos no processo de aprender significativamente.

No primeiro encontro, foram contemplados, nos trabalhos, conceitos relativos à origem do universo, além das galáxias, a formação e a evolução estelar e as constelações. Buscando diagnosticar os conhecimentos prévios dos participantes e estabelecer conexões destes com o conteúdo a ser abordado na ocasião, visualizaram-se dois documentários disponíveis na internet. $O$ primeiro, denominado "A origem do universo" $e$ disponível no endereço http://www.youtube.com/watch?v=BzJViANY7s4\&feature=fvwrel, apresenta, em pouco menos de cinco minutos, as ideias básicas da formação do universo. O segundo, intitulado "Big Bang" e disponível

em

http://www.youtube.com/watch?v=rfkyGKN39qo\&feature=BFa\&list=PLD1393FF0D09B366D,

apresenta, resumidamente, a teoria que procura explicar o processo de formação, constituição e expansão do universo.

A partir dessa visualização e de um breve comentário por parte do professor coordenador das atividades, os participantes foram convidados a elaborar a primeira versão do mapa conceitual dos tópicos estudados. Na sequência, os grupos apresentavam a versão inicial de seu mapa ao grande grupo e, após, se julgassem necessário, o reformulavam. As figuras 2 e 3 expõem as duas versões dos mapas produzidos pelo grupo 1 no decorrer do encontro. 


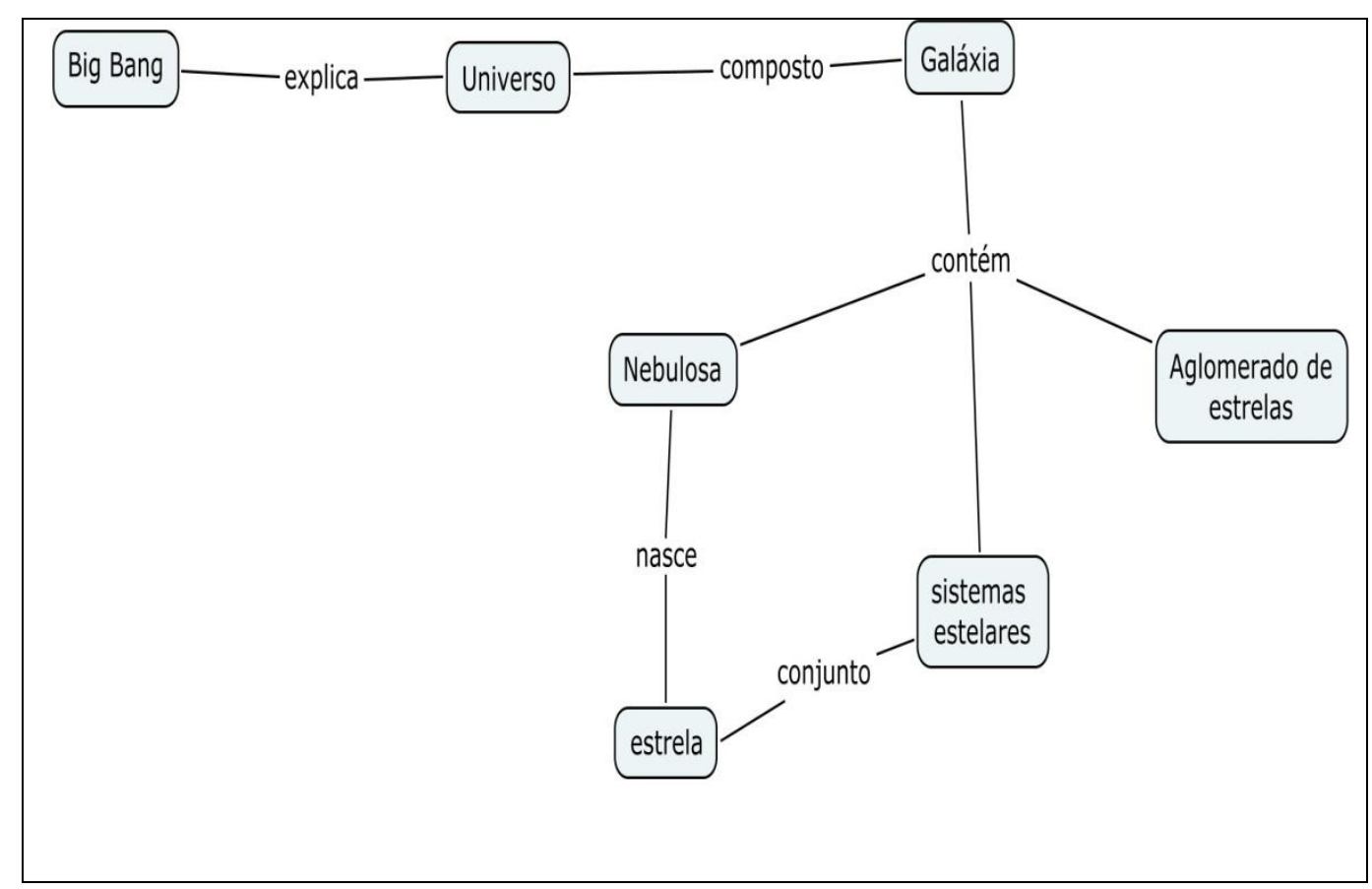

Figura 2: Versão inicial do mapa construído pelo grupo 1 no primeiro encontro

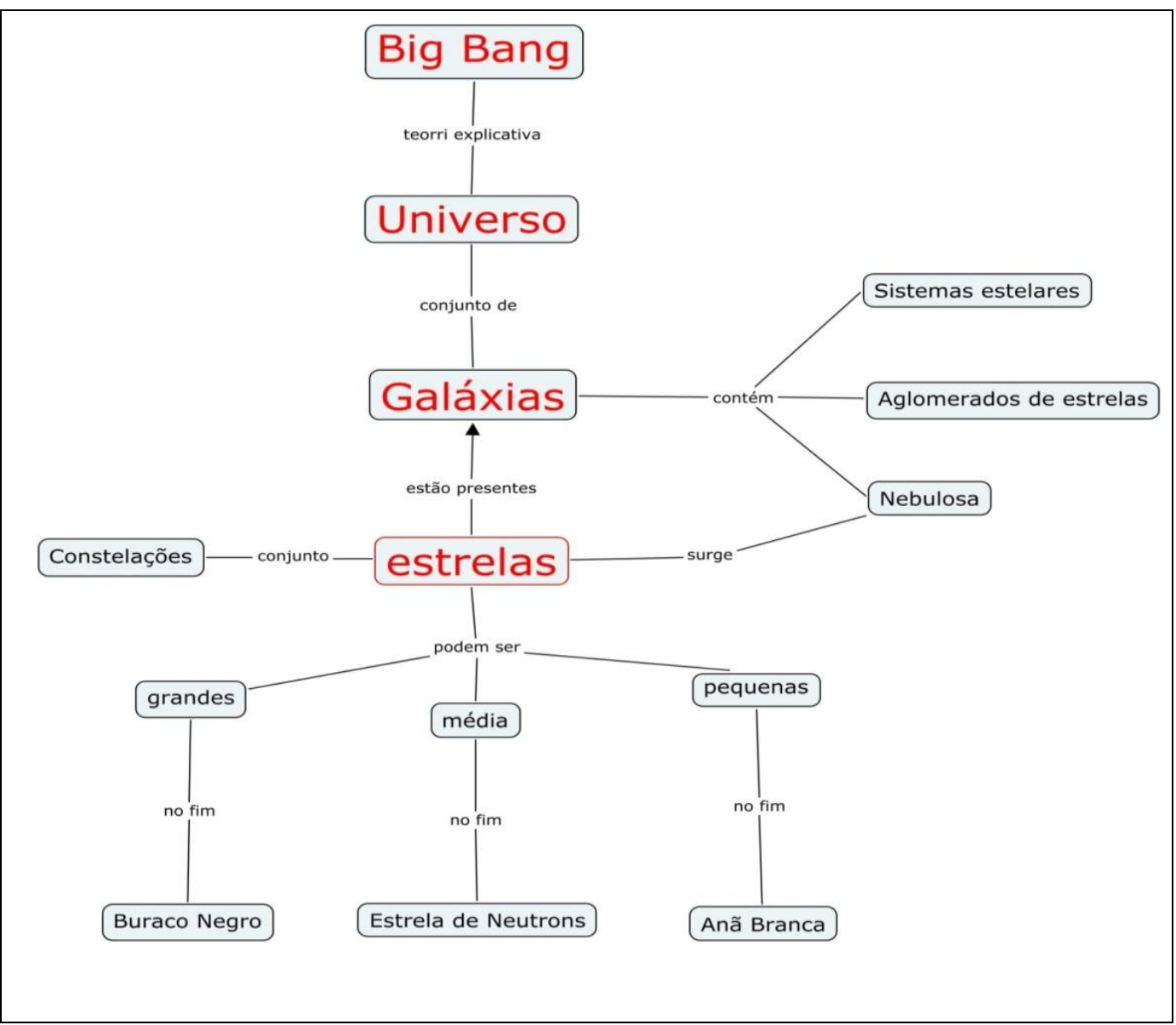

Figura 3: Versão final do mapa construído pelo grupo 1 no primeiro encontro 
Os conceitos relacionados com o Sol e o Sistema Solar foram abordados no segundo encontro. Inicialmente, foi apresentada aos participantes uma sequência de banners que continham imagens e diversas informações dos principais corpos celestes pertencentes ao Sistema Solar. Entre eles, destacam-se os que relacionam o Sol, o planeta Terra e a Lua. Com essa atividade, pretendia-se levar os participantes à compreensão significativa do sistema, que se constitui do Sol, o astro dominante, dos oito planetas com suas luas e anéis, além dos planetas anões, asteroides e cometas. Também era objetivo da atividade fazer uma conexão entre os conhecimentos prévios dos participantes e as novas informações que seriam abordadas na sequência. Com os subsunçores revitalizados e fundamentados no texto de apoio, os professores elaboraram a primeira versão do mapa conceitual correspondente aos tópicos do encontro. Assim como no encontro anterior, as versões iniciais foram apresentadas ao grande grupo para que os participantes compartilhassem significados e atingissem novas interpretações dos assuntos estudados, fortalecendo a aprendizagem significativa. As figuras 4 e 5 apresentam as duas versões dos mapas produzidos pelo grupo 2 no decorrer do encontro.

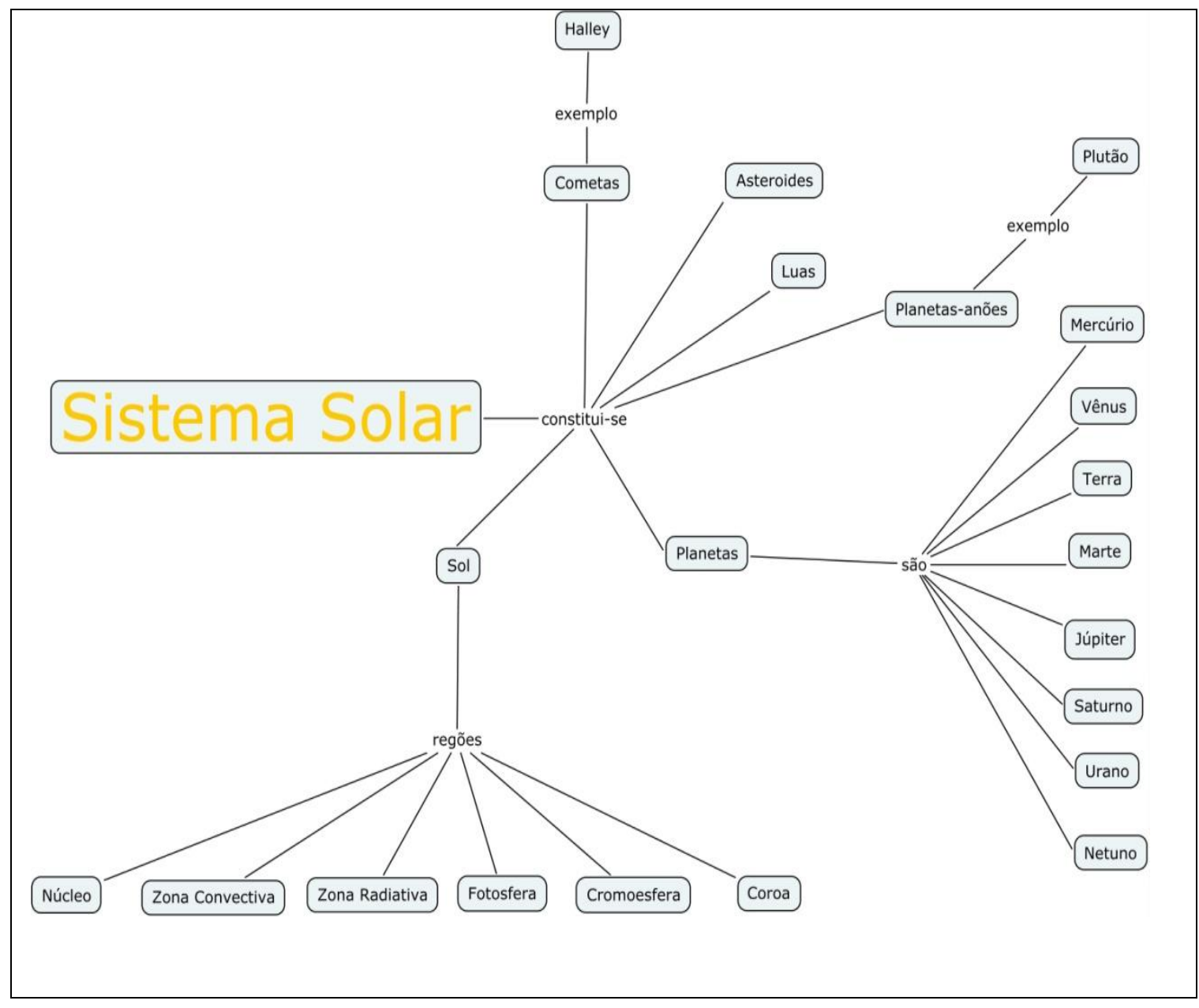

Figura 4: Versão inicial do mapa construído pelo grupo 2 no segundo encontro. 


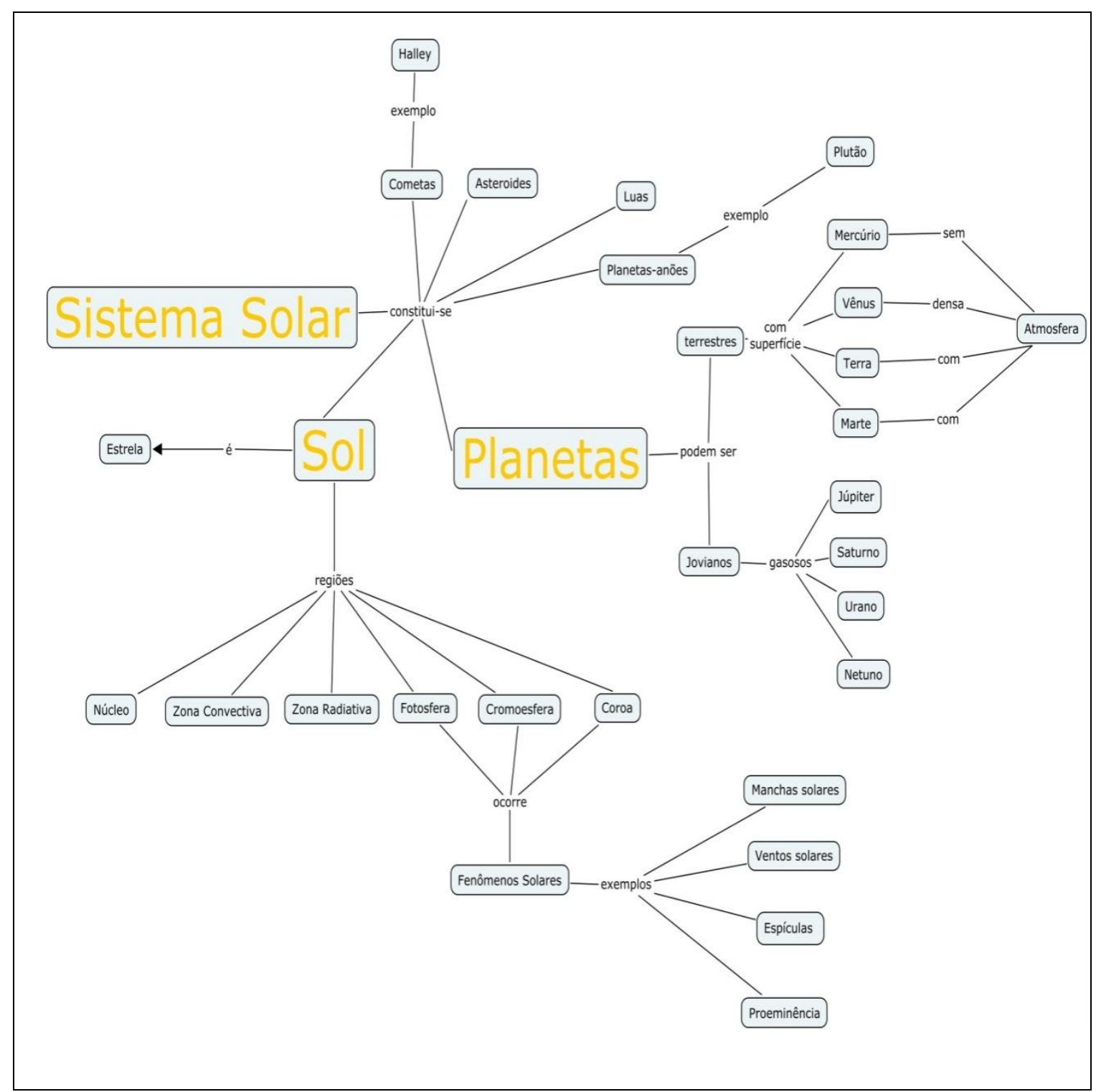

Figura 5: Versão final do mapa construído pelo grupo 2 no segundo encontro.

Para iniciar a discussão dos conceitos relacionados com o planeta Terra e seus movimentos, que, conforme Darroz (2010), tratam-se de conteúdos abordados com grande ênfase nos primeiros anos do ensino fundamental, solicitou-se que os participantes confeccionassem um objeto de ensino. Esse objeto, que simula os movimentos de rotação e translação terrestre, foi construído com base no roteiro elaborado por Santos (1996). Com o término da construção do material, cada professor foi motivado a simular os movimentos de rotação e translação da Terra, acreditando-se que essa atividade ligaria seus conhecimentos prévios aos conceitos desenvolvidos durante o encontro. Também, buscava-se criar condições para que, nos grupos, a partir dessas simulações e do texto de apoio, os participantes estabelecessem as relações entre as ideias, os conceitos e as proposições já estabelecidas em suas estruturas cognitivas e os novos conhecimentos, expressando essas combinações e 
recombinações nos mapas de conceitos objetivados para o encontro. As figuras 6 e 7 correspondem aos mapas iniciais e finais do grupo 3 elaborados na ocasião.

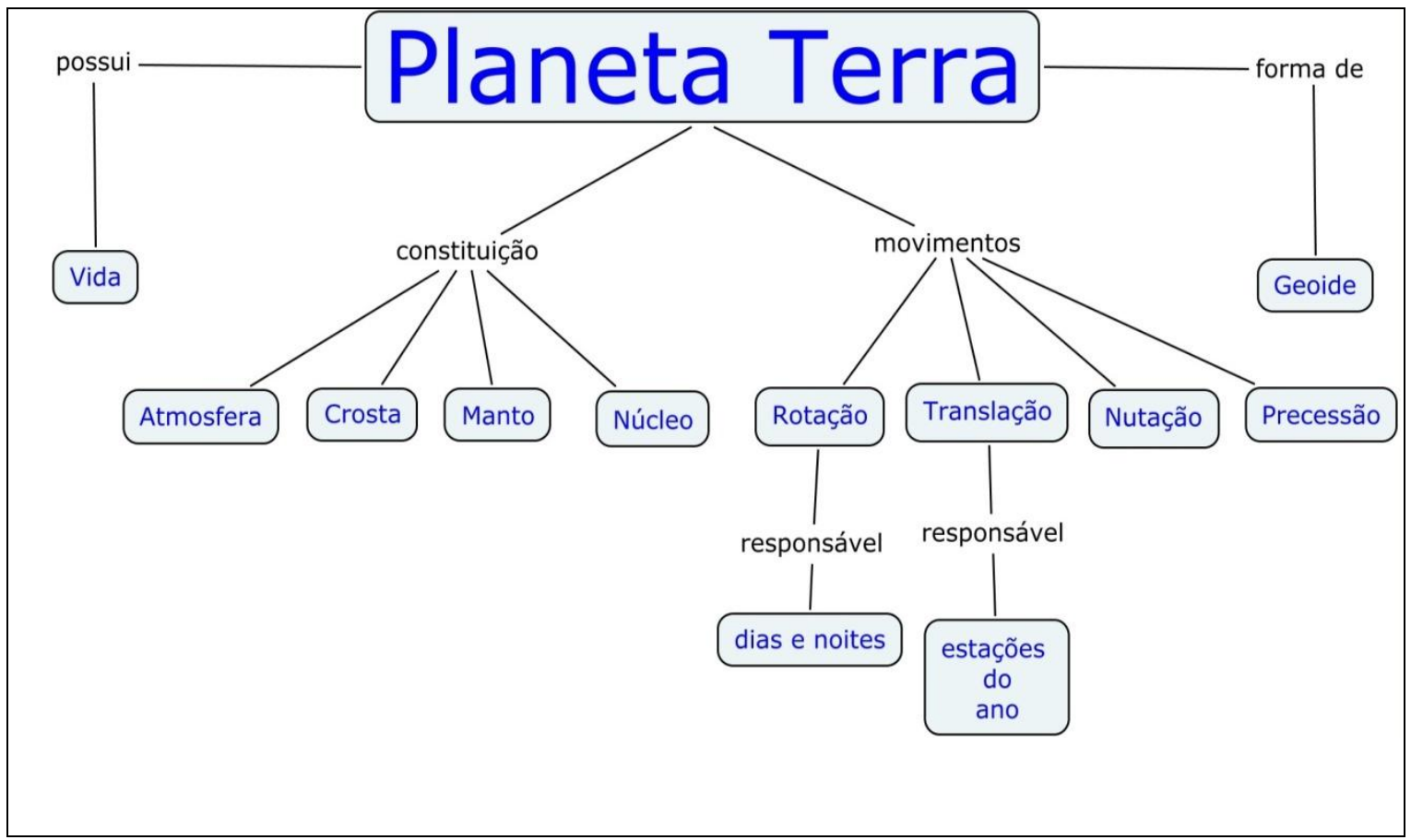

Figura 6: Versão inicial do mapa construído pelo grupo 3 no terceiro encontro.

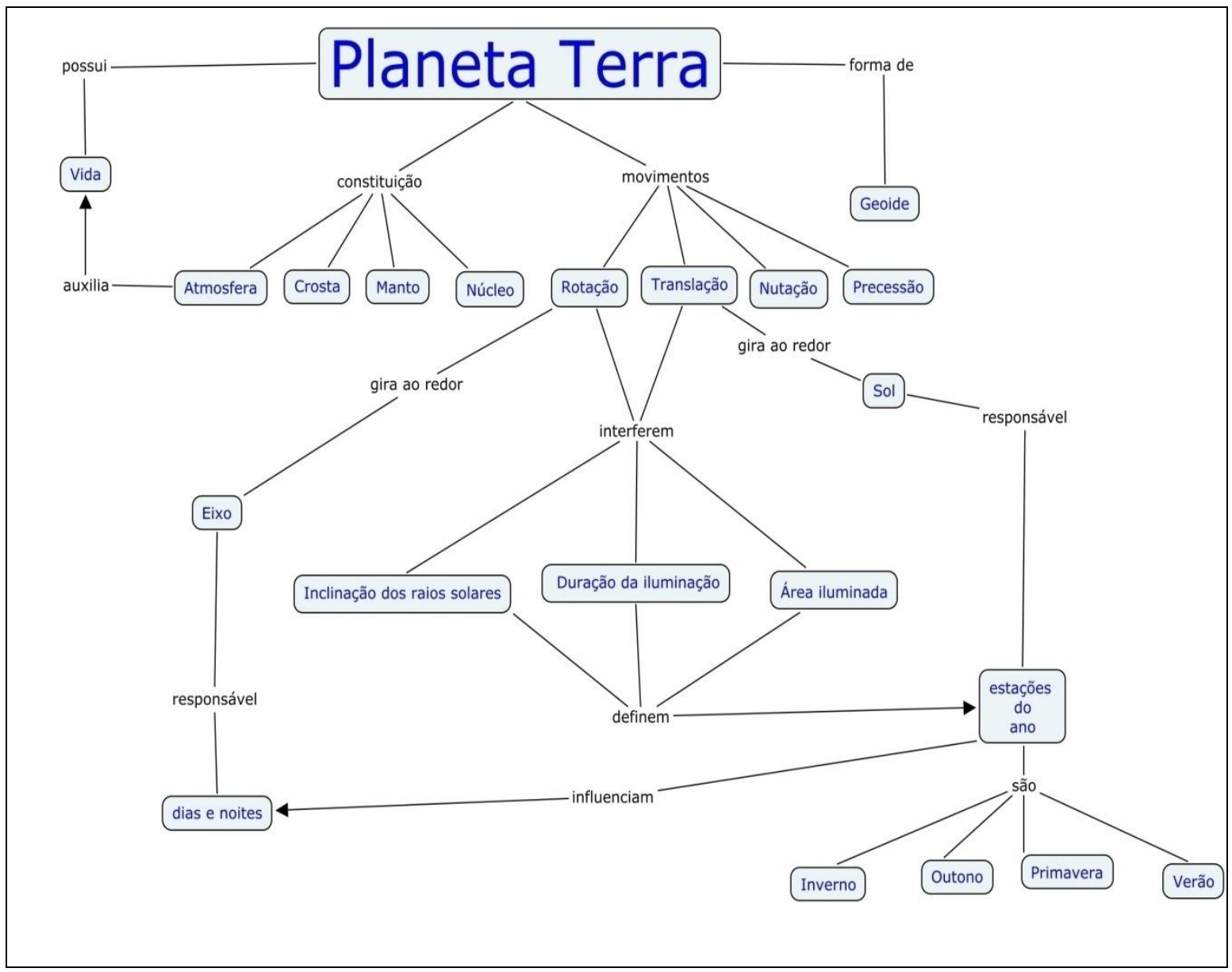

R. B. E. C. T., vol 6, núm. 3, set-dez.2013 ISSN - 1982-873X 
Figura 7: Versão final do mapa construído pelo grupo 3 no terceiro encontro.

$\mathrm{O}$ quarto e último encontro dividiu-se em dois momentos. No primeiro, foram abordadosos conceitos relativos à Lua, às suas fases e aos eclipses. Já no final, para coletar dados para essa pesquisa, aplicou-se novamente um questionário com perguntas relacionadas à astronomia. Cabe salientar que esse instrumento continha as mesmas questões do documento inicial e que se buscou, com base nele, identificar se os conceitos abordados no curso de capacitação foram incorporados à estrutura cognitiva dos professores.

O encontro foi iniciado pela atividade prática, que consistiu em um modelo didático simples para o movimento do sistema Terra-Lua. Para tanto, foi necessária uma sala escura com os seguintes recursos: fonte de luz (projetor de slides) representando o Sol, uma bola de isopor branca representando a Lua e um suporte para a bola localizada no centro do ambiente. A fim de relacionar os subsunçores com o tema abordado, os participantes relatavam oralmente o que observavam com referência à Lua (bola de isopor). Prosseguindo na atividade, ao assumirem novas posições na sala, cada estudante relatava como o satélite estava iluminado, descrevendo o seu aspecto (formato). O objetivo era levá-los a perceber a Lua toda iluminada com aspecto circular. A partir desse momento, orientou-se que todos caminhassem em círculo em torno da bola, lembrando que, no cosmos, quem está em movimento é a Lua (bola), e não as pessoas. Também, destacou-se que a Lua gira ao redor da Terra num plano cuja inclinação em relação ao orbital terrestre é de aproximadamente $5^{\circ}$. Ao girarem, os professores puderam perceber que a luminosidade varia de acordo com a posição que ocupam em relação a ela.

Nessa atividade, a intenção era de que os participantes reorganizassem e adquirissem novos significados, promovendo a diferenciação progressiva e a reconciliação integrativa, e que o conhecimento abordado se ancorasse no conceito subsunçor. Ela foi o ponto de partida para que, com base no texto de apoio, os professores efetuassem a construção do mapa conceitual referente à formação das fases lunares e dos demais fenômenos relacionados à Lua. Seguindo a metodologia definida para o curso de capacitação, a primeira versão foi apresentada e discutida no grande grupo e depois aperfeiçoada. As figuras 8 e 9 apresentam, respectivamente, a versão inicial e final dos mapas construídos no quarto encontro pelo grupo 4. 


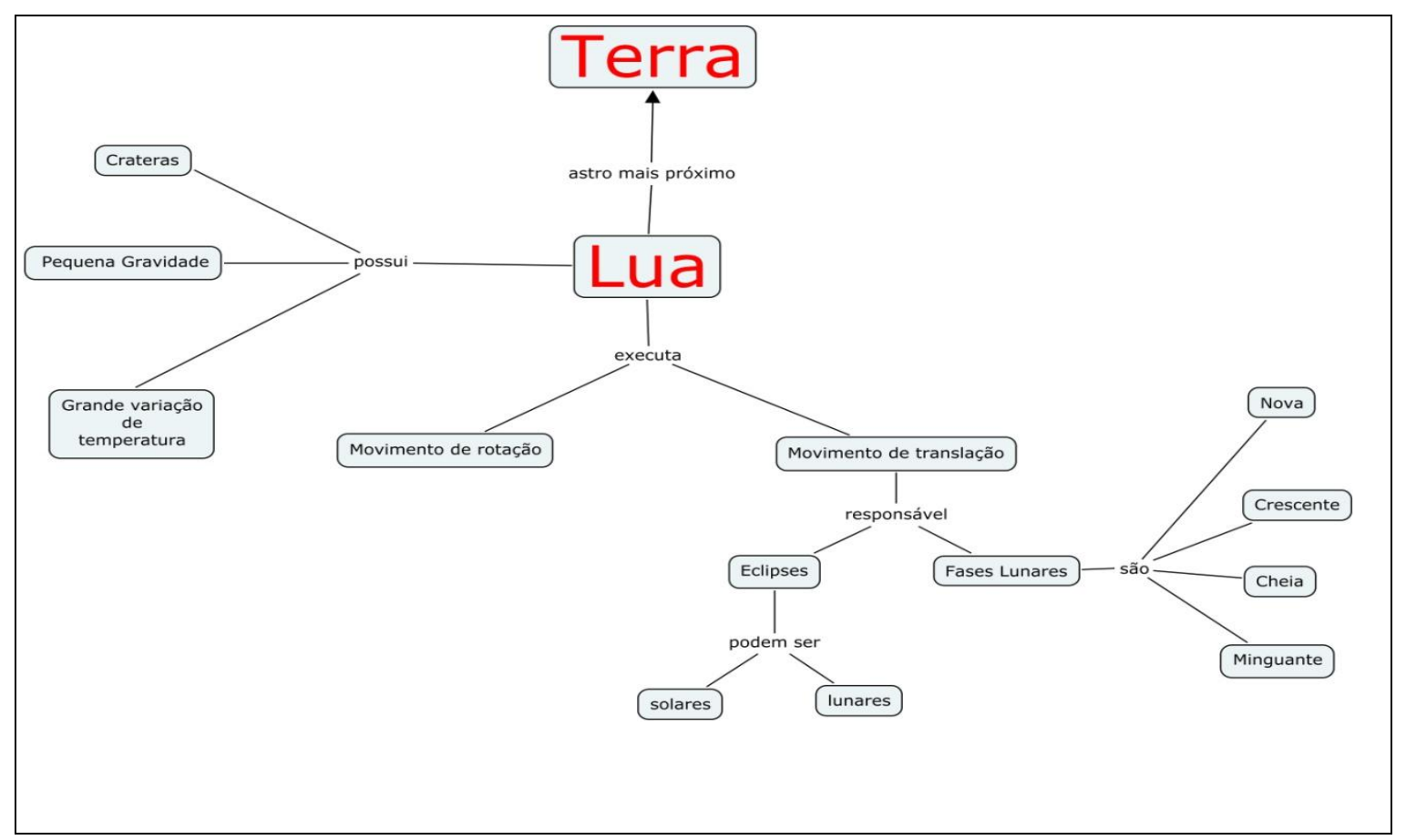

Figura 8: Versão inicial do mapa construído pelo grupo 4 no quarto encontro.

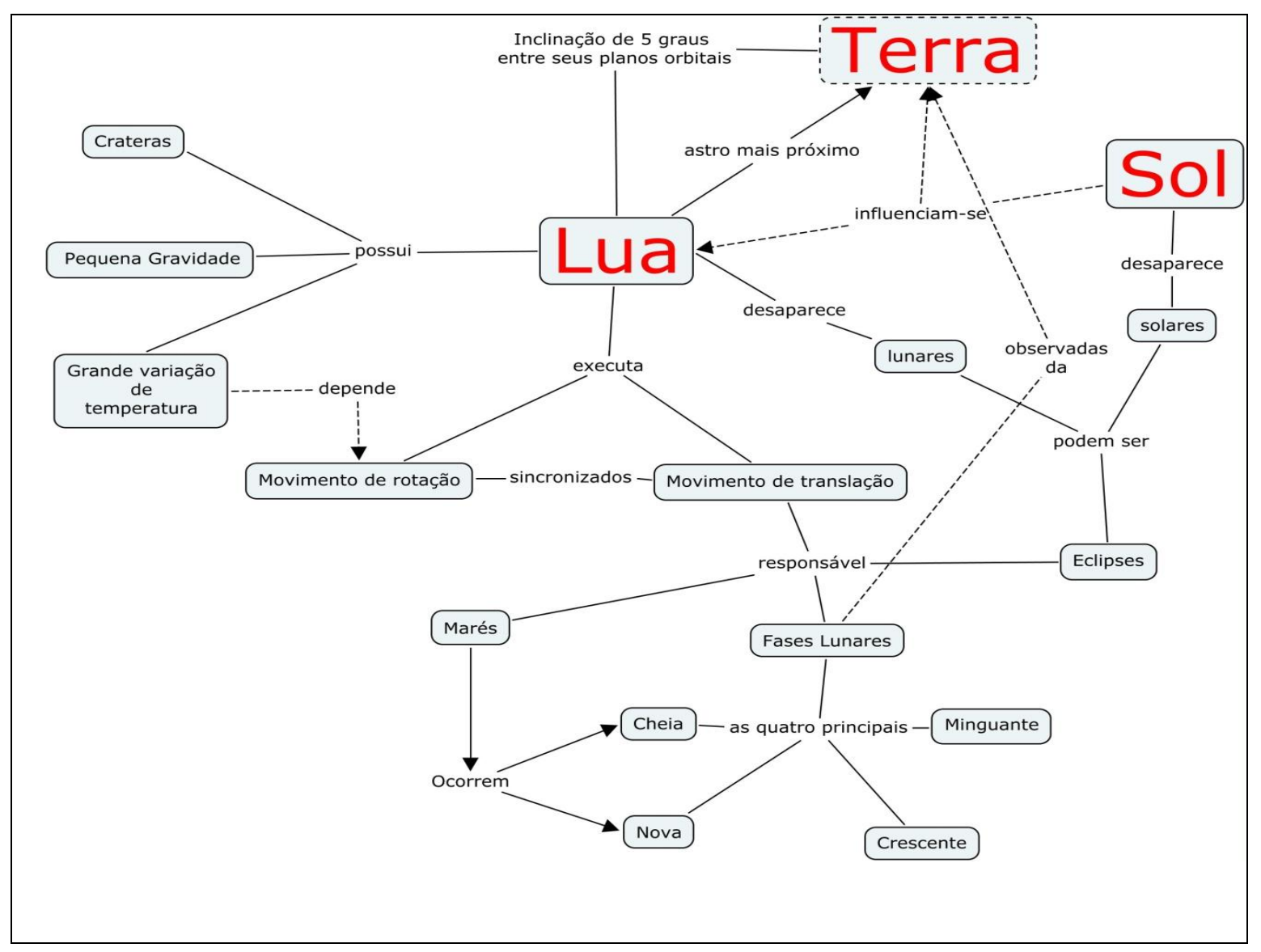

Figura 9: Versão final do mapa construído pelo grupo 4 no quarto encontro.

R. B. E. C. T., vol 6, núm. 3, set-dez.2013 ISSN - 1982-873X 


\section{Análise dos mapas e alguns resultados alcançados}

Ao analisar e comparar as versões iniciais e finais dos mapas elaborados no decorrer do curso de formação continuada, buscou-se identificar indícios que pudessem confirmar se a metodologia utilizada foi capaz de promover uma organização hierárquica dos conceitos abordados na estrutura cognitiva dos participantes. Além disso, visou-se a perceber se a forma como os participantes dispuseram e relacionaram os tópicos nos mapas aponta uma diferenciação progressiva e uma reconciliação integrativa que proporcione uma aprendizagem significativa dos temas estudados.

A versão inicial dos mapas construídos no primeiro encontro apresentou os principais conceitos abordados, porém, a forma de conexão linear apresentada pela maioria, somada à má exploração de conectores adequados, demonstrou que os participantes tiveram dificuldades em perceber, nitidamente, as relações entre os conceitos abordados no encontro. Acredita-se que a própria falta de hábito em construir mapas conceituais foi o principal obstáculo a ser superado pelos participantes.

Nas versões iniciais dos mapas construídos nos demais encontros, verificou-se uma melhor disposição dos conceitos principais, que ocupavam lugares estratégicos e estavam dispostos de maneira hierárquica. No entanto, é importante destacar que durante o processo de construção dos mapas os participantes não tinham muita clareza sobre quais eram os conceitos relevantes e as conexões existentes entre os assuntos abordados. Por esse motivo, constantemente, necessitavam reler os textos de apoio disponibilizados e, assim, apropriar-se de novos significados relacionados com os conceitos estudados para elaborar o mapa. Entende-se que esse ir e vir entre o material instrucional e a construção do mapa possibilitou aos professores uma reelaboração conceitual eficaz sobre os tópicos básicos de astronomia, servindo como oportunidade para elucidar possíveis lacunas sobre o assunto.

Nas comparações, notou-se uma significativa melhora entre as versões iniciais e finais, que pode ser atribuída aos momentos de apresentação e discussão dos mapas. Essas ocasiões, que se constituíram em um período importante do curso, proporcionaram, durante a explanação de cada grupo, oportunidades para que os colegas participassem com críticas e sugestões de alterações nos mapas e compartilhassem novos significados, somando-os ao que estavam estudando. Em todas as apresentações, houve debate e discussão, contribuindo muito para a melhor elaboração dos mapas finais e fortalecendo a aprendizagem significativa.

Em todas as versões finais, houve a manutenção da ordem de importância hierárquica dos conceitos, com ampliação do número de conceitos fundamentais. Nessas versões, ocorreram desdobramentos de conceitos mais globais em outros menos inclusivos, indicando a capacidade dos participantes em realizar a diferenciação conceitual progressiva. Observou-se, ainda, inserção de novos elos entre tópicos de ramos conceituais distintos, ou seja, determinados conceitos 
foram relacionados com outros aparentemente diferentes, demonstrando que os participantes conseguiram, também, promover a reconciliação integrativa dos temas abordados.

A análise dos mapas conceituais permitiu perceber como os conceitos básicos de astronomia estão organizados na estrutura cognitiva dos professores participantes do curso de formação continuada aqui descrito. Nessas representações, evidenciou-se a diferenciação progressiva e a reconciliação integrativa que os participantes conseguiram estabelecer quanto a esses conceitos, proporcionando um aumento significativo no índice de respostas corretas dadas ao instrumento aplicado no final do curso. Esse instrumento foi composto das mesmas questões aplicadas no instrumento inicial (Anexo 1).

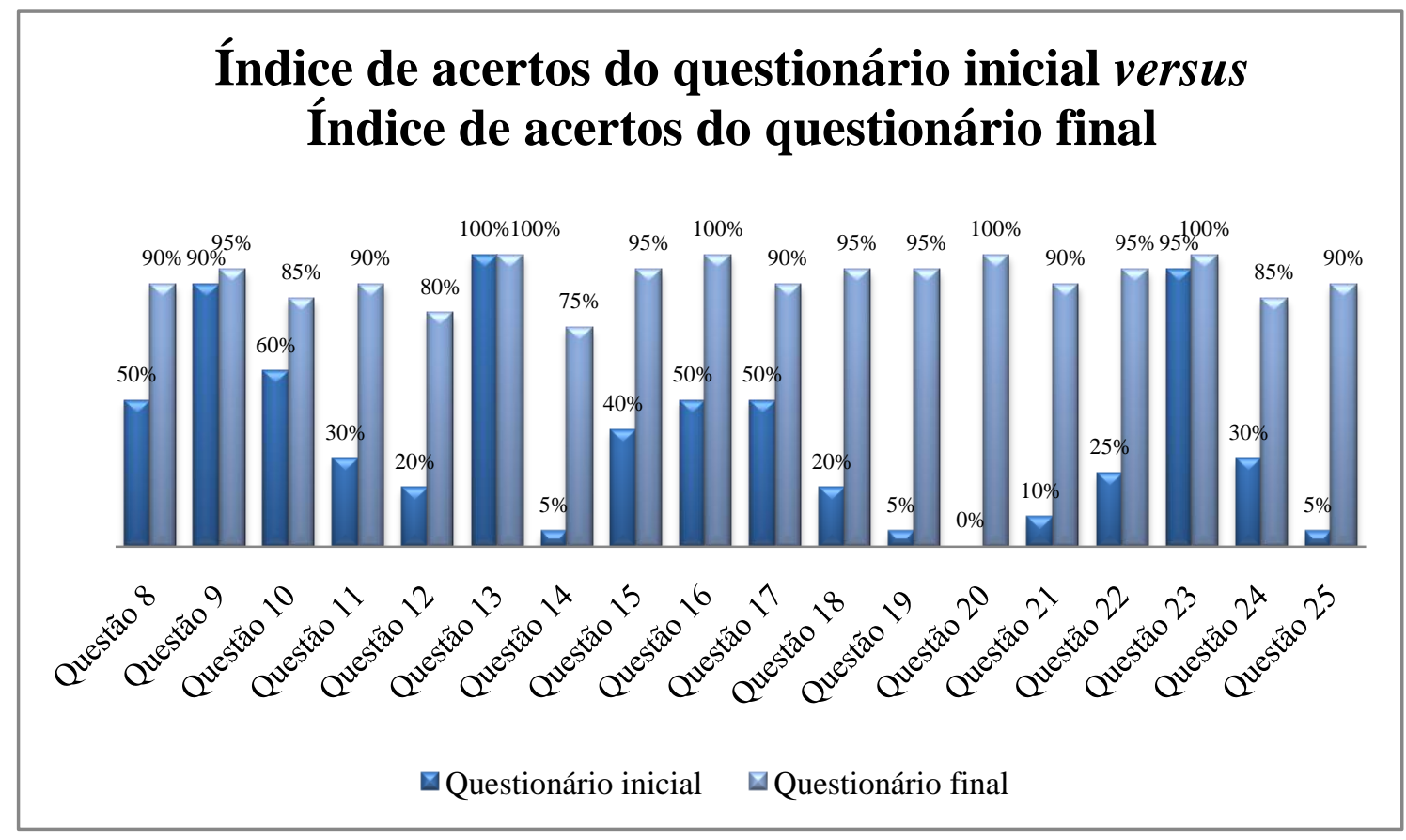

Figura 10: Índice de acertos das respostas dadas pelos professores ao questionário inicial versus índice de acertos das respostas dadas pelos professores ao questionário final.

Pelos resultados apresentados no gráfico da Figura 10, percebe-se que, após o curso de capacitação, $90 \%$ dos participantes consideram a teoria científica do Big Banga mais aceita para a explicação do surgimento do Universo. Nota-se, também, que $95 \%$ conseguem definir o que é uma estrela, $85 \%$ identificam onde elas nascem, $90 \%$ relacionam a sua fase final com a massa que esta possui e $80 \%$ definem uma constelação como um agrupamento aparente de estrelas.

Evidencia-se, ainda, no gráfico, que todos identificam o Sol como uma estrela e que $95 \%$ conseguem afirmar que a Lua é o corpo celeste mais próximo da Terra. Além disso, 95\% atribuem as fases lunares às diferentes posições ocupadas pelo astro em relação ao Sol e a Terra, à medida que orbita ao redor desta. Verifica-se, igualmente, que todos compreendem o Sistema Solar como um conjunto de astros formado pelo Sol, pelos oitos planetas, com suas luas e anéis, além dos planetas anões, asteroides e cometas, mas apenas $90 \%$ conseguem relacionar corretamente as 
sequências de astros em ordem de maior proximidade do Sol e $95 \%$ distinguem os planetas terrestres e identificam o maior dos planetas. De forma unânime, os participantes compreenderam que Plutão deixou de ser considerado um planeta, por não conseguir "limpar" as vizinhanças de sua órbita, e $85 \%$ atribuem a formação das estações do ano à inclinação dos raios solares, à área iluminada e à duração da iluminação.

Por fim, todos conseguiram explicar a sucessão dos dias e $90 \%$ relacionam o fenômeno dos eclipses à projeção da sombra de um astro em outro. Porém, o índice mais baixo das respostas corresponde ao entendimento do fenômeno conhecido popularmente por "estrela cadente", pois apenas $75 \%$ dos participantes conseguiram compreender que o fenômeno está associado a corpos rochosos provenientes do espaço que atingem a Terra e, ao entrarem na atmosfera terrestre com velocidade de dezenas de quilômetros por segundo, acabam aquecidos pelo atrito com o ar muito rapidamente, sendo, em geral, incinerados.

\section{Considerações finais}

Os resultados da experiência aqui descrita dão forças à hipótese deque uma metodologia com enfoque em um conteúdo significativo é fundamental para despertar no aprendiz o prazer pela ciência, a construção de significado e a valorização do que está sendo aprendido. Quando a metodologia é desenvolvida a um grupo de professores que percebem ligação direta entre os conteúdos a serem discutidos e os que já conhecem, interpretando-os como importantes para suas vidas, desenvolvem um potencial maior para a aprendizagem, afinal, esses novos conhecimentos passam a fazer sentido. Dessa forma, a ideia de desenvolver um curso de formação continuada sobre conceitos básicos de astronomia, fundamentado na teoria da aprendizagem significativa e no qual se recorra ao uso de mapas conceituais como recurso didático, pode ser considerada uma experiência bem-sucedida de complementar os currículos dos cursos de formação de professores.

Durante os encontros, os organizadores prévios e os materiais introdutórios tiveram uma função importante no processo de aprendizagem, pois se mostraram muito eficazes no estabelecimento das ligações entre os conhecimentos iniciais dos participantes e os temas abordados, servindo, ainda, como instrumento motivador para a sua aprendizagem. Notou-se que, quando se sente motivado à aprendizagem, o aprendiz se mostra livre para perguntar e debater sobre os conceitos apresentados.

No entanto, o significativo aumento nos índices de acerto, na comparação entre as respostas apresentadas nos questionários inicial e final, conduz à conclusão de que a utilização de mapas conceituais como recurso didático foi o ponto forte da experiência didática relatada. $\mathrm{Na}$ fase de elaboração dos mapas conceituais, os participantes precisaram representar e organizar seus conhecimentos básicos de astronomia, transformando em algo concreto e corretamente 
científico os conceitos que antes eram abstratos e, muitas vezes, envolviam interpretações equivocadas. Necessitaram, durante o processo de negociação e compartilhamento de novos significados, recorrer a diversas fontes para sanar suas dúvidas e, então, voltar à construção de seu mapa. Esse ir e vir entre a confecção do mapa e a procura de respostas auxiliou na construção de significados sobre os conceitos básicos de astronomia e fortaleceu a aprendizagem significativa.

Para um professor dos primeiros anos do ensino fundamental que precisa introduzir com seus alunos conceitos básicos de astronomia, a meta-aprendizagem torna-se uma necessidade. A busca de informações adicionais que possam preencher as lacunas conceituais deixadas ao longo de seu processo de formação é essencial para uma atividade profissional de excelência. Nesse sentido, a utilização de mapas conceituais como recurso didático constituiu-se e fortaleceu-se como uma estratégia facilitadora da tarefa de aprender a aprender, ao oportunizar aos professores a aquisição da habilidade indispensável para construir seus próprios conhecimentos.

Por tudo isso, o curso sobre conceitos básicos de astronomia foi exitoso e pode ser repetido, com conviç̧ão de sucesso, com professores dos primeiros anos do ensino fundamental. Todavia, nada impede que ele seja adaptado e que aborde diferentes conceitos das diversas áreas do conhecimento. Também, salienta-se que a utilização de mapas conceituais como recurso didático pode promover a aprendizagem significativa de qualquer assunto e em qualquer momento de escolarização.

\section{Referências}

BRASIL, Ministério da Educação e Cultura. Parâmetros Curriculares Nacionais: Ensino

Fundamental. Secretaria de Educação Fundamental, MEC/SEF, Brasília (1998).

BRETONES, P. S. Disciplinas introdutórias de Astronomia nos cursos superiores do Brasil.

Dissertação (Mestrado) - Instituto de Geociências, Universidade de Campinas, Campinas (1999).

$\mathrm{BISCH}, \mathrm{S}$. M. Astronomia no ensino fundamental: natureza e conteúdo do conhecimento de estudantes e professores. Tese (Doutorado) - USP, São Paulo (1998).

CAÑAS, A. J. et al. Cmap Tools: A knowledge modeling and sharing toolkit, technical report IHMC Cmap Tools 93-01, Institute for Human and Machine Cognition (2003).

COSTA, L. B. et al. Formação continuada em astronomia com professoras das séries iniciais no município de Canápolis, MG: um caso de parceria colaborativa. Em Extensão, 9, 1, 125-140 (2010). DARROZ, L. M. Uma proposta para trabalhar conceitos de astronomia com alunos concluintes de formação de professores na modalidade Normal. Dissertação (Mestrado Profissional em Ensino de Física) - Instituto de Física, UFRGS, Porto Alegre (2010). 
DARROZ, L. M; SANTOS, F. M. T; SARAIVA, M. F. O. Uma proposta para trabalhar conceitos de astronomia com alunos concluintes do curso de formação de professores na modalidade normal. Hipermídia de apoio ao professor de Física n. 20. Programa de Pós-Graduação em Ensino de Física - Instituto de Física, Universidade Universidade Federal do Rio Grande do Sul, Porto Alegre (2010). Disponível em <http://www.if.ufrgs.br/ppgenfis/index.php>.

FRANCO JUNIOR, F. C. Individual and historical development in science. Tese (Doutorado) Universityof Reading, Reading (1993).

GONZATTI, S. E. M. Um Curso Introdutório à Astronomia para a Formação Inicial de Professores de Ensino Fundamental, em nível médio.Dissertação (Mestrado Profissional em Ensino de Física) Instituto de Física, Universidade Federal do Rio Grande do Sul, Porto Alegre (2008).

LANGHI, R. Um estudo exploratório para inserção da Astronomia na formação de professores dos anos iniciais do Ensino Fundamental. Dissertação (Mestrado em Educação para a Ciência) Faculdade de Ciências, UNESP, Bauru (2004).

LANGHI, R; NARDI, R. Ensino de Astronomia: Erros conceituais mais comuns presente em livros didáticos de ciência. Caderno Brasileiro de Ensino Física,24, 1, 87-111 (2007).

LANGHI, R.; NARDI, R. Dificuldades interpretadas nos discursos de professores dos anos iniciais do Ensino Fundamental em relação ao ensino de Astronomia. Revista Latino-Americana de Educação em Astronomia - RELEA, 1, 2, 75-92 (2005).

LEITE, C. Os professores de ciências e suas formas de pensar a astronomia. Dissertação (Mestrado) - Instituto de Física, USP, São Paulo (2002).

LEITE, C; HOSOUME, Y. Os professores de ciências e suas formas de pensar a astronomia. Revista Latino-Americana de Educação em Astronomia - RELEA,4, 47-68 (2007).

MALUF, V. J. A Terra no espaço: a desconstrução do objeto real na construção do objeto científico. Dissertação (Mestrado) - UFMT, Cuiabá (2000).

MARQUES, N. L. R; ARAUJO, I. S. Investigando a formação de professores de ciências do ensino fundamental: uma experiência em Física Térmica. Revista Experiências em Ensino de Ciências EENCI, 5, 3, 131-152 (2010).

MOREIRA, M. A. Teorias de aprendizagem, EPU, São Paulo (1999).

MOREIRA, M. A. Mapas conceituais e diagramas V, Ed. do autor, Porto Alegre (2006).

MOREIRA, M. A; BUCHWEITZ, B. Novas estratégias de ensino e aprendizagem: os mapas conceituais e o Vê epistemológico, Plátano Edições Técnicas,Lisboa (1993).

QUEIROZ, G; AZEVEDO, C. A. A ciência alternativa do senso comum e treinamento de professores. Caderno Catarinense de Ensino de Física, 4, 1, 7-16 (1987). 
SANTOS D. Experiências de física na escola, EDIUPF, Passo Fundo (1996).

SILVA, D. F. Padrões de interação e aprendizagem em museus de ciências. Dissertação (Mestrado) - Instituto de Ciências Biomédicas, UFRJ, Rio de Janeiro (1999).

Luiz Marcelo Darroz: Doutorando em Educação em Ciências (UFRGS). Mestre em Ensino de Física. Especialista em Física. Graduado em MATEMÁTICA LP. Atualmente é professor da Universidade de Passo Fundo e coordenador do curso de Física da Universidade de Passo Fundo. Também é professor de física da Escola Redentorista Instituto Menino Deus e no Colégio Notre Dame Passo Fundo. Tem experiência na área de Física, com ênfase em Física, atuando principalmente nos seguintes temas: ensino de física, astronomia, aprendizagem significativa, formação de professores e ensino de ciências na educação básica. Idarroz@upf.br

Cleci Teresinha Werner da RosaGraduação em Matemática - Física (Universidade de Passo Fundo 1989); Especialização em Educação Matemática (UPF - 1991); Especialização em Ensino de Física (UPF - 1992); Mestrado em Educação (UPF - 2001); Doutorado em Educação Científica e Tecnológica (Universidade Federal de Santa Catarina - 2011). Atuou de 1990 a 2000 como professora de Física no Ensino Médio e desde 1993 é professora titular da Área e Curso de Física na Universidade de Passo Fundo, ministrando disciplinas nos cursos de graduação e pósgraduação, principalmente as relacionadas ao Ensino de Física/Ciências e Estágio Supervisionado. Atualmente é coordenadora da UPF Editora, coordenadora de Área no PIBID/Capes e Coordenadora do Programa de Pós-Graduação em Ensino de Ciências e Matemática (Mestrado Profissional) da UPF. É pesquisadora na área de Ensino de Física, investigando temas associados ao Laboratório didático de Física/Ciências nos diferentes niveis de ensino (atividades experimentais em Física); uso da metacognição como recurso estratégico para aprender e ensinar Física (aprender a aprender); ensino de Ciências (Física) nos anos iniciais do ensino fundamental; Robótica educacional. É revisora ad hoc de periódicos nacionais e internacionais e integra o corpo editorial da Editora UPF e de revistas internacionais na área de educação. cwerner@upf.br

Álvaro Becker da Rosa: Possui graduação em Engenharia Mecânica pela Universidade de Passo Fundo (1995) e mestrado em Ciências com área de concentração em Engenharia Biomédica, pelo Centro de Educação Tecnológica do Paraná (1999). Atualmente é pesquisador e professor adjunto da Universidade de Passo Fundo. Tem experiência nas áreas de: Engenharia Biomédica, com ênfase em ISO17025, ISO GUM; Física; pesquisa em Ensino de Física (laboratorio didático e séries iniciais); em processos da fabricação e automação industrial; e em inspeção de caldeiras e vasos de pressão.alvaro@upf.br

Carlos Ariel Samudio Pérez: possui graduação em Licenciatura En Física - Universidad de Panamá (1985), graduação em Profesorado En Física - Universidad de Panamá (1985), mestrado em Física pela Universidade Federal de Minas Gerais (1989) e doutorado em Física pela Universidade 
Federal do Rio de Janeiro (1994). Atualmente é professor titular da Universidade de Passo Fundo. Tem experiência na área de Física da matéria condensada, com ênfase em propriedades magnéticas de ligas metálicas. samudio@upf.br

Anexo 1- Questões que compuseram os instrumentos inicial e final para a coleta de dados Prezado professor, com o intuito de obter dados sobre nossa proposta, solicitamos que responda às questões abaixo:

Quanto à sua formação.

1. Qual é sua formação de nível médio?.

2. Possui graduação em nível superior? Em caso afirmativo, especifique o curso:

3. Possui título de especialista, mestre ou doutor? Em caso afirmativo, especifique o título e o curso

Quanto à sua atuação docente.

4. Em qual ano do ensino fundamental/anos iniciais você atua? E há quanto tempo você ministra aulas nesse nível de ensino?

5. Você ministra aulas que abordem conceitos de Astronomia? Em caso afirmativo, você sente-se seguro ao abordá-los durante sua ação docente?.

6. Durante sua formação, foram trabalhados conceitos relacionados com a Astronomia? Em caso afirmativo, diga com que profundidade.

7. Que fontes de informação você usa para elaborar suas aulas que abordam conhecimentos de Astronomia?.

Quanto aos seus conhecimentos sobre astronomia básica.

8. A teoria científica mais aceita para a explicação do surgimento do Universo é

a) a versão Bíblica do livro do Gêneses.

b) a do Big Bang.

c) a do estado Estacionário.

d) a da unificação das galáxias.

9. O que é uma estrela?

a) Estrela é uma esfera de plasma grande e luminosa que pela gravidade é mantida íntegra. 
b) Estrela é uma esfera de plasma grande que não tem luz própria.

c) Estrelas são corpos que refletem aluz do Sol.

d) Estrelas são satélites naturais dos planetas terrestres.

10. Uma estrela "nasce" (se forma)
a) no centro do Universo.
b) numa região do Universo com temperatura elevada.
c) em qualquer lugar do espaço, que possua energia.
d) no interior de uma Nebulosa.

11. O fim de uma estrela depende
a) da posição que ocupa no espaço.
b) da sua composição química.
c) de sua massa.
d) da sua temperatura.

12. Constelação é
a) um agrupamento de estrelas próximas.
b) um agrupamento de estrelas de mesmo tamanho.
c) um agrupamento de estrelas de mesma galáxia.
d) um agrupamento aparente de estrelas.

13. O Sol é
a) um asteroide.
b) um planeta.
c) uma galáxia.
d) uma estrela.

14. Uma estrela cadente é
a) uma pequena estrela que vem na direção da Terra.
b) um planeta Joviano.
c) um asteroide que está em uma trajetória de colisão com a Terra.
d) um cometa que vai ao encontro da Terra. 
15. A Lua é
a) o único satélite natural do Sistema Solar.
b) o corpo celeste luminoso mais próximo da Terra.
c) o maior satélite natural do Sistema Solar.
d) o corpo celeste mais próximo da Terra.

16. O Sistema Solar é constituído
a) pelo Sol e pelos oito planetas.
b) pelo Sol, pelos oitos planetas com suas luas e anéis, além dos planetas anões, asteroides e cometas.
c) pelo Sol, pela Terra e pela Lua.
d) pelas estrelas, pelo Sol, pela Terra, pelos planetas e pela Lua.

17. A ordem crescente de distância dos planetas do Sistema Solar ao Sol é
a) Mercúrio, Vênus, Terra, Marte, Júpiter, Saturno, Urano, Netuno e Plutão.
b) Mercúrio, Terra, Vênus, Marte, Júpiter, Saturno, Urano e Netuno.
c) Mercúrio, Vênus, Terra, Marte, Júpiter, Saturno, Urano e Netuno.
d) Mercúrio, Vênus, Marte, Terra, Júpiter, Saturno, Urano e Netuno.

18. Os planetas terrestres do Sistema Solar são
a) Terra, Marte, Saturno e Júpiter.
b) Mercúrio, Vênus, Terra e Saturno.
c) Mercúrio, Terra, Marte e Netuno.
d) Mercúrio, Vênus, Terra e Marte.

19. O maior planeta do Sistema Solar é
a) a Terra.
b) Júpiter.
c) Saturno.
d) Urano.

20. A partir de 2006, Plutão passou a ser considerado planeta-anão por
a) ser muito pequeno.
b) estar muito longe do Sol. 
c) por não ter a forma esférica.

d) por não conseguir "limpar" as vizinhanças de sua órbita.

21. As fases da Lua são

a) Nova e Cheia.

b) Nova, Crescente, Cheia e Minguante.

c) Crescente e Minguante.

d) os diferentes aspectos que o astro se apresenta para um observador terrestre ao ser iluminado pelos raios solares.

22. As fases da Lua devem-se
a) à projeção da sombra da Terra na superfície lunar.
b) ao fato de o astro possuir uma face clara e outra escura.
c) às diferentes posições ocupadas pela Lua em relação ao Sol e à Terra, à medida que orbita ao redor da Terra.
d) ao fato de o astro ser um corpo luminoso.

23. A origem da ocorrência das sucessões dos dias e das noites deve-se
a) à inclinação do eixo de rotação terrestre.
b) ao movimento de rotação da Lua.
c) ao movimento de rotação terrestre.
d) ao movimento de rotação e translação terrestre.

24. As estações do ano devem-se
a) ao Sol estar mais forte ou mais fraco.
b) à variação de distâncias entre o Sol e a Terra no decorrer do movimento de translação terrestre.
c) à inclinação dos raios solares, à área iluminada e à duração de iluminação.
d) exclusivamente à inclinação do eixo de rotação terrestre.

25. Um eclipse ocorre quando
a) um corpo entra na sombra de outro.
b) o Sol entra na sombra da Lua.
c) o Sol está entre a Lua e a Terra.
d) o Sol é atingido pela sombra da Terra.

R. B. E. C. T., vol 6, núm. 3, set-dez.2013 ISSN - 1982-873X 